\title{
Genetic analysis of inbreeding depression caused by chlorophyll-deficient lethals in Mimulus guttatus
}

\author{
JOHN H. WILLIS \\ Department of Ecology and Evolution, The University of Chicago, Chicago, IL 60637 U.S.A.
}

\begin{abstract}
Two Oregon populations of the partially self-fertilizing Mimulus guttatus, located on Iron Mountain and Cone Peak, were surveyed for the frequency of recessive chlorophyll-deficient lethals by selfing plants collected as seed from the wild. Allelism tests were used to determine the number of different loci with lethal alleles present in the carriers isolated in the population surveys. The frequency of carriers was 0.065 for the Iron Mountain population (23/356) and 0.024 for the Cone Peak population (8/327). Allelism tests of the 31 carriers isolated from both populations revealed the existence of 26 different independently acting loci and two different duplicate locus systems with lethal alleles. These results indicate that the component of inbreeding depression caused by chlorophyll-deficient lethals is not due to single locus heterozygote advantage and is probably caused by mutation-selection balance at many loci. Estimates of the genomic and per locus mutation rates for this class of lethals are in close agreement with those obtained in studies of chlorophyll-deficient lethals in several agricultural plant species. Genetic analysis of a California population of $M$. guttatus, reported in the literature to exhibit an unusually high per locus mutation rate and segregation distortion for a chlorophyll-deficient lethal, revealed that chlorophylldeficiency is inherited as a duplicate gene system. This mode of inheritance, not recognized previously, can explain the appearance of unusually high mutation rates and segregation distortion.
\end{abstract}

Keywords: chlorophyll-deficient mutations, genetic load, inbreeding depression, Mimulus, overdominance, recessive lethals.

\section{Introduction}

Inbreeding depression, the decreased fitness of inbred individuals as compared to outcrossed individuals, plays a major role in the evolution of plant and animal mating systems (Charlesworth \& Charlesworth, 1979; Lloyd, 1979; Lande \& Schemske, 1985; Charlesworth et al., 1990), in the production of economically important varieties of plants and animals (Falconer, 1981; Mather \& Jinks, 1982), and in the management of rare and endangered species (Soulé, 1986; Lynch \& Gabriel, 1990). In spite of the importance of inbreeding depression to diverse areas of ecology and evolutionary biology, the genetic cause of this phenomenon has not been completely resolved since two alternative hypotheses were proposed early this century. The most plausible explanation of inbreeding depression is the

Present address: Department of Biology, University of Oregon, Eugene, OR 97403 U.S.A. partial dominance hypothesis, in which many recessive or nearly recessive alleles are maintained in populations by mutation-selection balance. The alternative explanation posits that genetic load is primarily segregational and that alleles are maintained by heterozygote advantage. Experimental studies in plants and animals have shown that most of the inbreeding depression observed in experimental and natural populations is consistent with the partial dominance hypothesis, although overdominance cannot be ruled out in many cases (Simmons \& Crow, 1977; Wright, 1977; Crow \& Simmons, 1983; Jinks, 1983; Sprague, 1983; Charlesworth \& Charlesworth, 1987; Houle, 1989 ).

The genetic basis of inbreeding depression is difficult to analyse in most cases because of the contribution of large numbers of genes with individually small effects on the total genetic load. Genes with major effects on fitness, like lethals or sublethals, are much more amenable to genetic analysis than mildly delete- 
rious genes, and have been intensively studied in terms of their degree of dominance. In natural populations of Drosophila, for example, lethals seem to be largely recessive on average $(h \approx 0.02)$ and individually too rare to be maintained by overdominance (Dobzhansky \& Wright, 1941; Wright et al., 1942; Prout, 1952; Crow, 1964; Crow \& Temin, 1964; Simmons \& Crow, 1977; Crow \& Simmons, 1983; but see Mukai \& Burdick, 1959; Schnick et al., 1960; Dobzhansky \& Spassky, 1968). Studies of gametophytic and sporophytic lethals in natural fern populations show that most lethals are unique and non-allelic with other lethals, suggesting that the genetic load due to these genes is mutational (Klekowski, 1970, 1976, 1984; Ganders, 1972; Hedrick, 1987).

Lethal chlorophyll-deficient mutations are common in a wide variety of cultivated and natural plant species, and can be a major component of inbreeding depression (Crumpacker, 1967; Ohnishi, 1982). These mutations are recessive in their phenotypic expression, with mutant homozygotes germinating as white or yellow seedlings that can survive only for a few days. Some mutations produce pale green seedlings that can occasionally survive but most of the genes that have been studied are unconditionally lethal when homozygous (Crumpacker, 1967; Wettstein et al., 1971; Klekowski, 1988).

Heterozygotes for chlorophyll-deficient mutations can be extremely common in some plant populations and several studies have reported that these lethal genes were maintained at high frequency by overdominance (Gustafsson, 1947; Williams \& Brown, 1956; Apirion \& Zohary, 1961; Curran, 1963; Kiang \& Libby, 1972). Unfortunately, complete genetic analyses were not done in many of these studies and there is considerable doubt as to whether the apparent overdominance was caused by the locus itself, or even if the polymorphisms were due to genes at a single locus (Schuler, 1954; Crumpacker, 1967; Charlesworth et al., 1990).

Kiang \& Libby (Kiang, 1970; Kiang \& Libby, 1972) performed the most detailed of these genetic analyses in their study of an unusually frequent chlorophylldeficient mutation $(q \approx 0.17)$ in a largely clonal, perennial population of Mimulus guttatus in Plumas County, California. Genetic studies seemed to indicate that this was indeed a single-locus polymorphism and the authors attributed the high frequency of the lethal to heterozygote advantage during clonal growth (Kiang, 1970; Kiang \& Libby, 1972). Direct estimates were made of the single locus mutation rate by crossing normal homozygotes (WW), with heterozygote $(\mathrm{WW})$ and scoring the frequency of mutant seedlings (Kiang \& Libby, 1972). This experiment yielded an ususually high single locus mutation rate estimate of $1.3 \times 10^{-4}$. The authors also found slight segregation distortion in favour of the mutant allele in $\mathrm{WW} \times \mathrm{Ww}$ crosses, but not in $W w \times W w$ crosses (Kiang, 1970; Kiang \& Libby, 1972). They concluded that, although there was evidence of a high mutation rate and segregation distortion, the polymorphism was probably maintained by heterozygote advantage. The claims of overdominance in this study and in the studies cited above are in direct contrast to other studies of cultivated species which show that many genes can mutate to cause chlorophyll-deficient lethals and that much of the load can be explained by mutation-selection balance (Crumpacker, 1967; Wettstein et al., 1971; Ohnishi, 1982; Klekowski, 1988).

This study will address the genetic basis of inbreeding depression caused by chlorophyll-deficient lethals in two annual populations of the monkeyflower $M$. guttatus. These partially self-fertilizing populations are located on Iron Mountain and Cone Peak in Oregon's Western Cascades, and exhibit considerable inbreeding depression for many major components of fitness and morphological traits (Willis, 1991). Inbred families also frequently contain chlorophyll-deficient seedlings that die shortly after germination. The goals of this study were to determine the frequency of heterozygotes in both populations for chlorophylldeficient mutations and to determine, by allelism, tests whether the carriers were all heterozygous at the same locus or at many different loci. A high frequency of a single lethal allele would support the overdominance hypothesis, while polymorphism due to rare alleles at many loci is taken as evidence for the partial dominance hypothesis. This study will also include a genetic analysis of the chlorophyll-deficient mutations present in the California population of $M$. guttatus studied by Kiang \& Libby (Kiang, 1970; Kiang \& Libby, 1972), with the purpose of determining whether their unusual results of a high per locus mutation rate and segregation distortion might be explained by aspects of the genetic system not recognized in their experiments.

\section{Materials and methods}

\section{Population surveys}

The plants that were screened for chlorophyll-deficient mutations were obtained as seed from each population in August 1989, as described in detail in Willis (1991). Approximately 350 randomly chosen plants were sampled from each population and seeds from each of these families were germinated in the Universtiy of Chicago's greenhouse in the late fall of 1989. One seedling from each family was randomly selected and 
transplanted individually into a $3.5^{\prime \prime}$ square pot. Plants were grown to flowering in the greenhouse, and selfpollinated during the spring of 1990 . Up to 20 selfed seeds from each plant (mean seed number per selfed family $=18.9$ ) were planted into 98-cell flats filled with ProMix in late May 1990. All seeds from a particular family were planted in the same cell. The total number of selfed families planted was 356 for the Iron Mountain population and 327 for the Cone Peak population. Flats were transported to the greenhouse at the University of Oregon in Eugene, Oregon, in early June 1990. During this time flats were watered and repositioned frequently to minimize environmental differences between flats. The emergence of any chlorophyll-deficient seedlings was noted. Most seeds had germinated by the end of the trip in early June. Three days after the flats had been transferred to the University of Oregon greenhouse, all selfed families were censused for the number of germinated seeds and for the presence of any chlorophyll-deficient seedlings.

\section{Allelism tests}

The parents of any selfed family containing chlorophylldeficient seedlings were retained at the University of Chicago greenhouse and maintained by clonal propagation. During the fall, winter, and spring of 1990-91, these carriers were self-fertilized and were intercrossed in all possible combinations. Seeds from the selfings and the allelism tests were germinated during the winter on filter paper in an incubator set with long, warm days $\left(15 \mathrm{~h} \sim 24^{\circ} \mathrm{C}\right)$ and short, cool nights $\left(9 \mathrm{~h} \sim 4^{\circ} \mathrm{C}\right)$. In the spring, seeds were germinated under natural light in the greenhouse mist bench in 48-cell flats filled with ProMix. The phenotypes of seedlings were scored as they emerged. Crosses were repeated until at least 12 seedlings were obtained for each allelism test. A minimum of 12 seedlings were scored per cross to reduce the probability of falsely scoring a cross as non-allelic (the chance of observing 12 normal seedlings from a cross between two carrierss at the same locus is $0.75^{12}=0.032$ ). The majority of the allelism tests resulted in far more than 12 seedlings (mean number of seedlings scored per cross $=42.5$ ).

\section{Genetic analysis of the California population}

Seed samples were collected in late August 1989, from the population of $M$. guttatus studied by Kiang \& Libby (Kiang, 1970; Kiang, 1972; Kiang \& Libby, 1972). This population is located along Schneider Creek in Plumas County, California, and the seed samples were collected from plants in Sections B, C, and D described in fig. 2 of Kiang \& Libby (1972). Many unrelated carriers for chlorophyll-deficient mutations were isolated by the procedure followed in the surveys of the Iron Mountain and Cone Peak populations. Six of these carriers were retained for more detailed genetic analysis because of the wide variety of segregation ratios observed in the selfed progeny of these plants. Allelism tests were then conducted on these six carriers in the manner described above.

\section{Results}

\section{Population surveys}

Table 1 shows the results of the population surveys for heterozygous carriers of chlorophyll mutations. The frequency of parental plants that were heterozygous for one or more recessive lethal was 0.065 for the Iron Mountain population and 0.024 for the Cone Peak population. A G-test confirmed that the frequency of carriers was significantly lower in the Cone Peak population than in the Iron Mountain population (Table 1). Germination rates for the selfed seeds were 0.829 $( \pm 0.0134)$ for Iron Mountain and $0.669( \pm 0.0184)$ for Cone Peak (Willis, 1991). Two hundred and one of the 327 selfed families that were planted from Cone Peak produced 12 or more seedlings, compared with 251 of the 356 families planted from Iron Mountain. These moderate germination rates, coupled with the

Table 1 Frequency of selfed families which contained chlorophyll-deficient seedlings. The populations are significantly different in the frequency of carriers for chlorophyll-deficient lethals according to a $G$-test of independence with 1 d.f. $(G=6.64, P<0.05)$

\begin{tabular}{llll}
\hline & $\begin{array}{l}\text { Families with } \\
\text { chlorophyll-deficient } \\
\text { Peedlings }\end{array}$ & $\begin{array}{l}\text { Total number } \\
\text { of families }\end{array}$ & Frequency \\
\hline $\begin{array}{l}\text { Iron Mountain } \\
\text { Cone Peak }\end{array}$ & 23 & 356 & 0.065 \\
\hline
\end{tabular}


relatively small number of seeds planted per family, means that there was probably some bias against detecting families segregating for recessive chlorophyll mutations, so the frequency of carriers could have been underestimated.

\section{Segregation ratios of the carriers}

Tables 2 and 3 show the numbers of normal and chlorophyll-deficient seedlings obtained after selfing the carriers identified in the population surveys. Of the 31 carriers isolated from both populations, 25 had segregation ratios that were not significantly different from single locus recessive expectations. All but one of these (carrier 61) had ratios of progeny that were significantly different from expectations based on duplicate gene inheritance $(15: 1)$, in which only the double homozygote is lethal. Only 19 selfed seedlings were scored for carrier 61, but because of the results of the allelism tests discussed below, this carrier was classified as having segregation ratios consistent with single locus expectations and not consistent with a 15:1 ratio. When all 1,980 selfed seedlings from these 26 carriers are anlaysed together (mean of 76 seedlings per carrier), the ratios of the seedlings are not significantly different from 3:1 (Table 2).

Six carriers produced segregation ratios that were significantly different from single locus expectations (Table 3). The seedling ratios of four of these carriers $(41,198,494$, and 552) were also significantly different from the pattern expected with duplicate gene expression. The proportion of chlorophyll-deficient seedlings for carriers 41 and 552 were consistent with the 9:7 ratio expected when the carrier is heterozygous for two independent chlorophyll mutations, such that homozygosity at one locus is sufficient for the expression of the mutant phenotype. These two carriers had seedling frequencies that were significantly different from the 27:37 ratio expected with segregation at three independent loci. The proportion of lethal seedlings from carrier 494 was significantly greater than that expected with segregation at one or two independent recessive chlorophyll mutations, but was consistent with the three locus expectation (27:37). Carrier 198 produced too many chlorophyll-deficient seedlings for single locus or duplicate gene expectations, but too few for the ratios with two or three independent loci. The two most plausible explanations of this unusual seed-

Table 2 Summary of the segregation ratios of the 25 carriers whose ratios were not significantly different from 3:1 expectations. All carriers had significantly different ratios from that expected from duplicate gene inheritance (except for carrier no 61 - see Results and Discussion). The mean number of seedlings scored per carrier was 76.2. A chi-squared test with 1 d.f. revealed that the pooled data was not significantly different from 3:1 expectations $\left(\chi^{2}=1.077\right)$

\begin{tabular}{llll}
\hline Phenotype & $\begin{array}{l}\text { Observed number } \\
\text { of seedlings }\end{array}$ & $\begin{array}{l}\text { Expected number } \\
\text { of seedlings }\end{array}$ & $(O-E)^{2} / E$ \\
\hline Normal & 1505 & 1485 & 0.269 \\
Chlorophyll-deficient & 475 & 495 & 0.808 \\
\hline
\end{tabular}

Table 3 Segregation ratios of carriers that were significantly different from $3: 1$. Also presented are the $\chi^{2}$ values with different modes of inheritance. The ratio of normal to chlorophyll-deficient seedlings for each carrier was compared, using $\chi^{2}$ tests with 1 d.f., to ratios expected with inheritance due to one locus $(3: 1)$, two independent loci $(9: 7)$, three independent loci $(27: 37)$, and duplicate loci (15:1)

\begin{tabular}{lrllllll}
\hline \multirow{2}{*}{ Population } & $\begin{array}{l}\text { ID } \\
\text { No. }\end{array}$ & $\begin{array}{l}\text { Number of } \\
\text { normal seedlings }\end{array}$ & $\begin{array}{l}\text { Number of } \\
\text { albino seedlings }\end{array}$ & $\begin{array}{l}\text { Single locus } \\
\chi^{2} \text {-value }\end{array}$ & $\begin{array}{l}\text { Two loci } \\
\chi^{2} \text {-value }\end{array}$ & $\begin{array}{l}\text { Three loci } \\
\chi^{2} \text {-value }\end{array}$ & $\begin{array}{l}\text { Duplicate loci } \\
\chi^{2} \text {-value }\end{array}$ \\
\hline Iron Mountain & 41 & 100 & 75 & $29.76^{* * *}$ & 0.06 & $16.05^{* * *}$ & $400.24^{* * *}$ \\
& 198 & 200 & 114 & $21.14^{* * *}$ & $7.07^{* * *}$ & $59.55^{* * *}$ & $484.10^{* * *}$ \\
Cone Peak & 494 & 7 & 20 & $34.68^{* * *}$ & $10.09^{* *}$ & 2.93 & $211.97^{* * *}$ \\
& 552 & 64 & 42 & $12.90^{* * *}$ & 0.73 & $14.48^{* * *}$ & $201.48^{* * *}$ \\
Iron Mountain & 132 & 49 & 5 & $7.14^{* *}$ & $26.10^{* * *}$ & $52.19^{* * *}$ & 0.83 \\
& 161 & 29 & 3 & $4.17^{*}$ & $15.37^{* * *}$ & $30.78^{* * *}$ & 0.53 \\
\hline
\end{tabular}

$*=P<0.05 ; * *=P<0.01 ; * * *=P<0.001$. 
lings ratio are that carrier 198 is indeed heterozygous at two independently acting loci, but either the mutant homozygotes have low germination success or the loci are linked in repulsion phase. At this point there is not sufficient data to distinguish between these two possibilities. Two carriers, 132 and 161, produced seedling ratios that were consistent with the hypothesis of heterozygosity at two duplicate loci, such that homozygosity at both loci was necessary for expression of the mutant phenotype.

\section{Allelism tests}

Of the 465 possible crosses between all 31 carriers, 418 were successfully completed with more than 12 seedlings per cross. One cross, $161 \times 368$, resulted in only four seedlings but it was included in the crosses discussed below because it produced a single chlorophyll-deficient seedling. A total of 17,806 seedlings were scored from these 419 crosses, yielding a mean of 42.5 seedling per cross. Twelve of the 419 crosses resulted in the segregation of mutant seedlings. The number of normal and chlorophyll-deficient seedlings from each of these crosses is presented in Table 4.

The first six crosses listed in Table 4 involve all possible crosses between the four carriers 61,161 , 368, and 553. Carrier 553 originated in the Cone Peak population, while the other three carriers were from Iron Mountain. Carrier 161 was identified in the segregation tests as being heterozygous at two duplicate loci, such that homozygosity at both loci was necessary for expression of the mutant phenotype (Table 3). Carriers
368 and 553 were identified as being heterozygous at a single locus, while the number of progeny scored for carrier 61 was too small to distinguish between these two possibilities. The fact that mutant progeny were observed in the crosses between the double heterozygote 161 and the other carriers suggests that carriers 368,553 , and possibly 61 were homozygous mutant at one of the duplicate loci and heterozygous at the other locus. If this hypothesis is correct, segregation ratios of crosses between 161 and the other three genotypes should result in $7: 1$ seedling ratios, while crosses among carriers 61,368 , and 553 should all produce segregation ratios of $3: 1$. Table 4 shows that the three crosses among carriers 61,368 , and 553 resulted in ratios that were consistent with a $3: 1$ ratio and significantly different from a 7:1 ratio. These results confirm that carrier 61, like 368 and 553, was heterozygous at only one locus. All the crosses between these four carriers involving carrier 161 produced proportions of chlorophyll-deficient seedlings consistent with the expected 7:1 ratio, but only one of these three crosses had sufficient numbers of progeny to reject the 3:1 segregation hypothesis. Carrier 132, which was identified earlier as being heterozygous at two duplicate loci (Table 3 ), did not produce any mutant progeny when crossed to the four carriers $61,161,368$, and 553 ( mean number of progeny per cross $=39.5$ ), suggesting that the putative duplicate locus system of carrier 132 is different from the system just analysed.

Three of the remaining six allelic crosses involved the three carriers 79,552 , and 626 , all of which originated from the Cone Peak population. Carriers 79 and

Table 4 Segregation ratios for those crosses between carriers that resulted in at least one chlorophyll-deficient seedling. Ratios of normal to chlorophyll-deficient seedlings were compared to ratios expected in crosses between carriers both heterozygous at the same locus (3:1) and between a carrier heterozygous for one locus of a duplicate system and homozygous recessive at the other locus of a duplicate locus system (e.g. Aabb or aaBb), and a carrier heterozygous for both of those loci (expected ratio $7: 1$ )

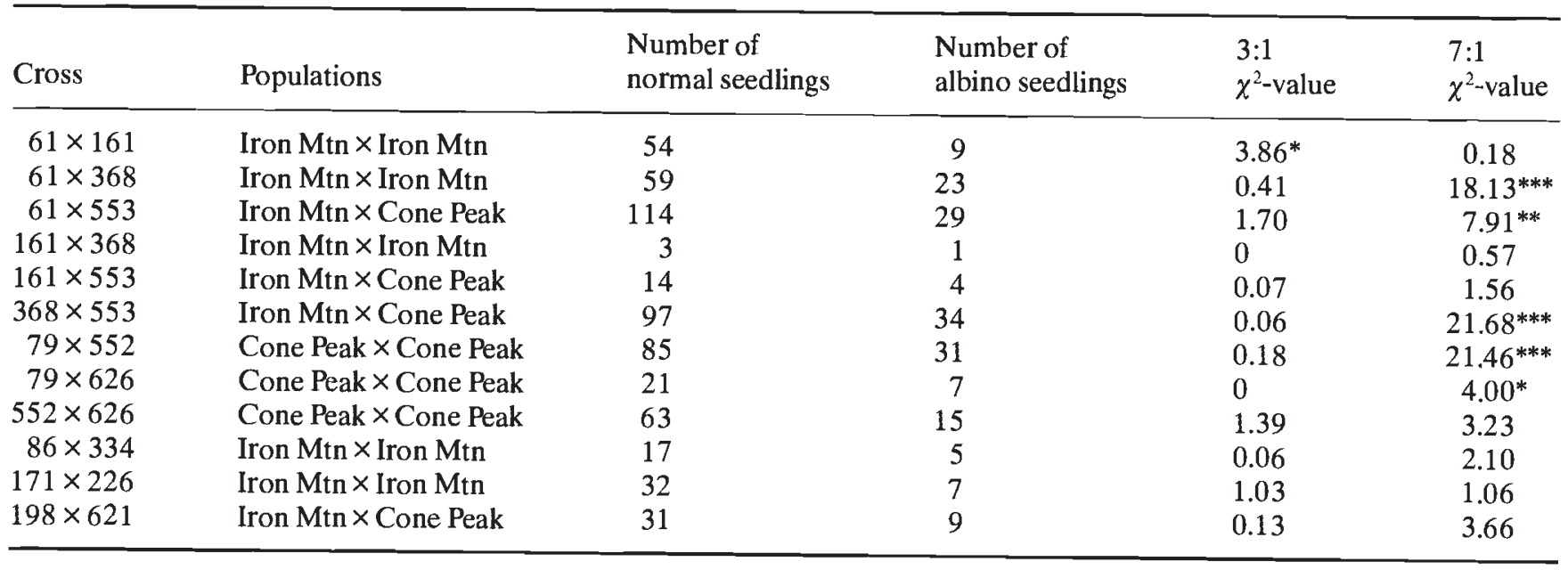

${ }^{*} P<0.05 ;{ }^{* *} P<0.01$; ${ }^{* * *} P<0.001$. 
626 produced selfed ratios of chlorophyll-deficient seedlings consistent with single locus segregation and different from 15:1 expectations, while carrier 552 appeared to be heterozygous at two independently acting loci (Table 3). The final three allelic crosses involved six unique carriers, five of which were classified as being single-locus heterozygotes. The other genotype, carrier 198, was probably heterozygous for two independent loci (Table 3 and above).

Table 5 shows the frequency of allelism in crosses among the 26 carriers known to be heterozygous for one of more independently acting loci. Carriers involved in the two duplicate gene systems $(61,132$, 161,368 , and 553) were excluded from the analysis because they do not provide information about the alternative selective hypotheses operating at independently acting loci. Of the 325 possible crosses, 291 were completed, with a total of 12,298 seedlings scored. Six of these crosses produced chlorophylldeficient seedlings, so the rate of allelism is 0.0206 . These results suggest that the vast majority of carriers in the Iron Mountain and Cone Peak populations are heterozygous at unique loci.

The number of different complementation groups (loci) present in these 26 carriers, which are known to

Table 5 Frequency of allelism among the chlorophylldeficient mutations. The four carriers involved in the two duplicate two locus systems have been excluded, leaving only those crosses between the 26 carriers with recessive lethal segregation (IDs 61, 161, 368, 553, and 132 excluded)

\begin{tabular}{llll}
\hline $\begin{array}{l}\text { Total number of } \\
\text { seedlings scored }\end{array}$ & $\begin{array}{l}\text { Number of } \\
\text { allelic crosses }\end{array}$ & $\begin{array}{l}\text { Total number } \\
\text { of crosses }\end{array}$ & $\begin{array}{l}\text { Allelism } \\
\text { frequency }\end{array}$ \\
\hline 12298 & 6 & 291 & 0.0206 \\
\hline
\end{tabular}

be heterozygous for one or more independently acting loci, can be determined by examination of the allelism results (Table 4) and the selfed segregation ratios of multiply heterozygous carriers (Table 3 ). First, the maximum number of loci present in the four carriers that were heterozygous for more than one lethal and not exhibiting duplicate gene inheritance is 9 , assuming that carrier 198 was heterozygous at two loci (Table 3). Without taking into account the results of the allelism tests, this suggests a maximum of 31 different complementation groups (nine from the four carriers discussed above, plus 22 from the remaining single locus carriers). When the allelism results are taken into account (Table 4), it is clear that several of these carriers were heterozygous for the same lethal allele, so that the true number of different loci must be less than 31 . The actual number of different complementation groups, based on the allelism results (Table 4), is therefore 26 . There are an additional two complementation groups when one considers the two duplicate-acting two-locus systems.

\section{Genetic analysis of the California population}

Table 6 shows the segregation ratios of six carriers that were retained for genetic analysis. The first three carriers listed in the table clearly display the expected $3: 1$ ratios of normal to mutant seedlings. The number of normal and mutant progeny of carriers 5 and 13 do not follow the expected single-locus ratios but are perfectly consistent with the expectations with duplicate gene inheritance. A third pattern of inheritance is apparent in the progeny of carrier 6: the ratio is different from single and duplicate gene expectations, but is consistent with the 9:7 ratio expected with segregation at two independent loci. Allelism tests resulted in some chlorophyll-deficient seedlings being produced in all

Table 6 Segregation ratios for six carriers obtained from the Schneider Creek population in Plumas County, California, studied by Kiang \& Libby (1972). The ratio of normal to chlorophyll-deficient seedlings for each carrier was compared to expectations using $\chi^{2}$ tests with 1 d.f.

\begin{tabular}{rrllll}
\hline ID & $\begin{array}{l}\text { Number of } \\
\text { normal seedlings }\end{array}$ & $\begin{array}{l}\text { Number of chlorophyll- } \\
\text { deficient seedlings }\end{array}$ & $\begin{array}{l}3: 1 \\
\chi^{2} \text {-value }\end{array}$ & $\begin{array}{l}15: 1 \\
\chi^{2} \text {-value }\end{array}$ & $\begin{array}{l}9: 7 \\
\chi^{2} \text {-value }\end{array}$ \\
\hline 4 & 93 & 24 & 1.26 & $40.62^{* * *}$ & $25.67^{* * *}$ \\
7 & 228 & 79 & 0.09 & $198.88^{* * *}$ & $40.50^{* * *}$ \\
8 & 84 & 23 & 0.70 & $42.44^{* * *}$ & $21.53^{* * *}$ \\
5 & 154 & 14 & $24.89^{* * *}$ & 1.24 & $85.63^{* * *}$ \\
13 & 140 & 9 & $28.57^{* * *}$ & 0.01 & $86.10^{* * *}$ \\
6 & 90 & 71 & $31.32^{* * *}$ & $393.63^{* * *}$ & 0.01 \\
\hline
\end{tabular}

$*=P<0.05 ; * *=P<0.01 ; * * *=P<0.001$. 
crosses. Crosses between carriers with 15:1 ratios and the other four carriers all resulted in ratios of seedlings that were consistent with a 7:1 ratio but statistically different from all other usual one or two gene ratios. All crosses between the four carriers not exhibiting a 15:1 ratio resulted in seedling ratios consistent with 3:1 expectations.

\section{Discussion}

This study found that the frequency of heterozygotes for recessive chlorophyll-deficient lethals was 0.065 in the Iron Mountain population and 0.024 in the Cone Peak population. When the results of the segregation tests of the carriers and the allelism tests are taken into account, it appears that there were 26 different (nonallelic) loci and two different duplicate gene systems heterozygous for recessive chlorophyll-deficient lethals in the sample of 31 carriers isolated from the two populations. The rate of allelism between the 26 carriers not involved in either duplicate locus system was 0.0206 , a rate which is quite close to the $2-3$ per cent allelism rates for nearly recessive lethals within populations of Drosophila (Dobzhansky \& Wright, 1941; Wright et al., 1942).

The large number of independent loci segregating for chlorophyll-deficient lethals in these two $M$. guttatus populations is clearly inconsistent with the hypothesis of single locus overdominance as the cause of this component of inbreeding depression, although the possibility of weak overdominance at all of these loci cannot be ruled out. The results are much more consistent with mutation-selection balance at many loci, such that the mutant allele frequency at any single locus is very small. The number of nuclear genes capable of mutating to chlorophyll-deficient lethals is not known in any plant species but the number of loci characterized in maize (Riman, 1963; Crumpacker, 1967) and in barley (Wettstein et al., 1971) surpass 100 and the actual number could be several times higher.

It is possible to estimate the rate of mutation to chlorophyll-deficient lethals per genome per generation by assuming that the mutations analysed in this study are maintained by mutation-selection balance and by using data on the frequency of heterozygotes and on the rate of self-fertilization in the populations (Ohta \& Cockerham, 1974). If it is assumed that the chlorophyll-deficient lethals are completely recessive, then the genomic mutation rate to lethals, $U$, can be estimated as $U=H S / 2$, where $H$ is the frequency of individuals heterozygous for lethal genes and $S$ is the selfing rate (Ohta \& Cockerham, 1974; Charlesworth et al., 1990). Given the frequency of carriers in each population (Table 1), and from knowledge of the carriers involved in the two duplicate gene systems, estimates of $H$ are 0.054 for Iron Mountain (19/352) and 0.021 for Cone Peak (7/326). Estimates of the selfing rates, $S$, for both populations were low $(0-0.09)$ in 1989 , and somewhat higher $(0.25-0.45)$ in 1990 (Willis, 1991). If the conservative assumption is made that the populations are mainly outcrossing on average $(S \approx 0.05)$, then the estimates of the genomic mutation rate are $U=1.4 \times 10^{-3}$ for Iron Mountain and $U=5.3 \times 10^{-4}$ for Cone Peak. The frequency of recessive lethals in a population is quite sensitive to occasional population bottlenecks or periods of high self-fertilization, so these different estimates of $U$ might reflect a history of higher selfing rates or smaller population sizes in Cone Peak, and not true differences in the mutation rate (Wright, 1969; Lande \& Schemske, 1985). Approximate mutation rates per locus can be obtained by dividing the genomic rate estimates by the number of loci capable of mutating to chlorophylldeficient lethals. With the reasonable assumption that the number of potentially mutable loci is 200-500 (Crumpacker, 1967; Wettstein et al., 1971), the estimated mutation rates per locus are on the order of $10^{-6}$, a value that is strikingly similar to the estimated per locus mutation rate to lethals in Drosophila of $2 \times 10^{-6}$ (Crow \& Simmons, 1983).

These mutation rate estimates are likely to be underestimates of the true mutation rate becaues of a possible ascertainment bias in detecting heterozygotes. In addition, if the populations are more highly selfing even occasionally, as was indicated by the moderate outcrossing rate estimates in 1990 , then $U$ would have to be higher to account for the observed frequency of carriers. Partial dominance of the chlorophyll-deficient lethals would also result in larger estimates of the genomic mutation rate. Lethals segregating in Drosophila populations are not completely recessive and the dominance coefficient has been estimated to be about 0.02 (Crow \& Simmons, 1983). Finally, the calculation used to estimate $U$ was derived for an infinite population. Finite population size will tend to decrease the average frequency of lethals (Wright, 1937; Nei, 1968; Robertson \& Narain, 1971; Lande \& Schemske, 1985) so that a larger $U$ would be needed to explain the observed values of $H$.

The estimates of $U$ obtained in this study are of similar magnitude to estimates obtained for several agricultural species. Crumpacker (1967) reviewed an early study of maize (Hayes \& Brewbaker, 1924) and estimated that the mutation rate to chlorophyll-deficient alleles per gamete was $0.002\left(U=4 \times 10^{-3}\right)$. Ohnishi (1982) studied the frequency of chlorophylldeficient mutants in populations of cultivated buckwheat and from these data Klekowski (1988) estimated 
the genomic mutation rate to be $4 \times 10^{-4}$. A very similar direct estimate of $U=6.3 \times 10^{-4}$ was obtained in barley (Jørgensen \& Jensen, 1986).

The results of Kiang and Libby's study of the California $M$. guttatus population stand in sharp contrast to the results presented here (Kiang, 1970, 1972). In their study, direct estimates were made of the single locus mutation rate by crossing normal homozygotes (WW) with heterozygotes $(\mathrm{Ww})$ and scoring the frequency of mutant seedlings (Kiang \& Libby, 1972). The genotypes used in their experiment were determined by selfing plants collected in the field and germinating at least 30 seeds: plants that failed to produce chlorophylldeficient seedlings were classified as WW. Their experiment yielded as unusually high single locus mutation rate estimate of $1.3 \times 10^{-4}$. The authors also found slight segregation distortion in favour of the mutant allele in $\mathrm{WW} \times \mathrm{Ww}$ crosses but not in $\mathrm{Ww} \times \mathrm{Ww}$ crosses (Kiang, 1970; Kiang \& Libby, 1972).

The progeny and allelism tests conducted in the present study clearly demonstrate that the genetics of chlorophyll-deficiency in the Schneider Creek population is considerably more complex than supposed by Kiang and Libby (Kiang, 1970, 1972; Kiang \& Libby, 1972). The common allele studied by Kiang and Libby was actually part of a duplicate gene system, where the mutant allele at one locus was far more common than the mutant allele at the other locus. This would result in the single heterozygotes ( $\mathrm{aaBb}$ or $\mathrm{Aabb})$ being far more common than the double heterozygote $(\mathrm{AaBb}$ ) and therefore a 3:1 ratio would frequently be observed. The segregation ratio of carrier 6 also suggests that other independent genes can also produce chlorophylldeficient seedlings, as one would expect. The high single-locus mutation rate and the peculiar form of segregation distortion reported by Kiang and Libby (Kiang, 1970; Kiang \& Libby, 1972) could be explained if occasionally a double heterozygote was misidentified as WW and used in the mutation rate or segregation distortion studies. Misclassification of WW genotypes could have happened because sometimes as few as 30 selfed progeny were scored (Kiang \& Libby, 1972), resulting in an appreciable chance that no chlorophyll-deficient seedlings would be observed in the progeny tests of $\mathrm{AaBb}$ plants. Rare crosses between $\mathrm{AaBb}$ (thought to be WW) and $\mathrm{aaBb}$ and Aabb (thought to be $\mathrm{Ww}$ ) in the mutation rate study would produce some chlorophyll-deficient seedlings and this could account for the observed single-locus mutation rate that was two or three orders of magnitude greater than expected. Similarly, the occasional inclusion of a double heterozygote in the segregation distortion study could result in deviations from the expected 1:1 ratios of WW to Ww. Of the normal pro- geny produced when $\mathrm{AaBb}$ is crossed to $\mathrm{aaBb}$ or Aabb, five out of seven will be expected to segregate for chlorophyll-deficient seedlings when selfed. Although some chlorophyll-deficient seedlings should have been produced in these crosses, they might not have been detected if family sizes were small or if they were excluded because of being attributed to pollen contamination. An excess of progeny that segregate for lethal genotypes would also be produced if the carriers $\mathrm{a} a \mathrm{Bb}$ or $\mathrm{Aabb}(\mathrm{Ww})$ were occasionally crossed to $\mathrm{AABb}$ or $\mathrm{AaBB}$ (WW), respectively. The fact that segregation distortion was never observed in crosses between known single heterozygotes $(\mathrm{Ww}=\mathrm{aaBb}$ or Aabb) makes sense under this alternative hypothesis. It is still not clear why lethal recessive alleles are so frequent in this population but if plants reproduce primarily clonally (Kiang \& Libby, 1972), so that recessive genes are very rarely exposed to selection, then mutation pressure alone might be a sufficient explanation.

Duplicate gene inheritance of chlorophyll-deficient lethals was also found in the Iron Mountain and Cone Peak populations. A similar pattern of inheritance of chlorophyll-deficient lethals is well known in maize (Demerec, 1923; Crumpacker, 1967) and in tobacco (Clausen \& Cameron, 1950). Mutation-selection balance and the evolution of inbreeding depression at duplicate loci is more complex than when mutations act independently because selection against the mutants occurs only in the double homozygote. Fisher (1935) first pointed out, in his discussion of tetraploidy, that in an infinite population with equal mutation rates of two loci, the frequency of the double homozygous lethals will equal the mutation rate. This means there can be many different combinations of the mutant allele frequencies at the two loci at equilibrium, such that the frequencies of the two lethal alleles may either equal or asymmetrical by any amount.

The amount of inbreeding depression generated by mutation-selection balance at duplicate loci was studied by Lande \& Schemske (1985) and, assuming that the mutant frequencies were the same at both loci, was found to be half that with mutation-selection balance at a single locus. The assumption of equal gene frequencies at the two loci meant that most deleterious genotypes would be produced by selfing in the double heterozygotes. If gene frequencies are not equal at the two loci, as might be expected with drift or unequal mutation rates, then the inbreeding depression will more closely resemble that with single locus inheritance. Fixation of one of the deleterious alleles can occur when there are unequal mutation rates at the two loci (Christiansen \& Frydenberg, 1977) or when the population size is small (Haldane, 1933; Nei, 1969; 
Ohno, 1972; Nei \& Roychoudhury, 1973; Maruyama \& Takahata, 1981). Gene silencing by the fixation of null alleles at duplicate loci has occurred frequently in the evolution of presumed ancient polyploids like salmonid and catostomid fishes (Allendorf, 1976; Ferris \& Whitt, 1977; Li, 1980) and ferns (Werth et al., 1985; Bryan \& Soltis, 1987; Gastony, 1991; Werth \& Windham, 1991). It is not possible to obtain accurate estimates of the frequencies of double heterozygotes at either duplicate system found in the Iron Mountain and Cone Peak populations in this study because the family sizes in the population survey were too small to avoid substantial ascertainment bias. However, it seems unlikely that the mutant gene frequencies are equal at the two loci, at least for the system involving carrier 161 , because in both populations several carriers were detected that were homozygous for the lethal allele at one locus and heterozygous at the other locus. If there is substantial asymmetry in the mutant allele frequencies, then the magnitude of inbreeding depression at these duplicate loci is expected to be roughly similar to that caused by normal single locus inheritance.

The fraction of the total inbreeding depression in the Iron Mountain and Cone Peak populations attributable to chlorophyll-deficient lethals is rather small. In the inbreeding depression experiments in Willis (1991), any chlorophyll-deficient seedlings were scored as not having germinated, so that genetic load due to these genes was expressed only during the germination stage of the life cycle. In the field and greenhouse experiments of Willis (1991), differences between selfed and outcrossed individuals were expressed at almost all life-history stages measured in both populations, and inbreeding depression during the germination stage contributed only a fraction of the total measured inbreeding depression. In addition, no more than a small fraction of the inbreeding depression expressed during seed germination was caused by segregation of chlorophyll-deficient lethals. Only about 5 per cent of selfed families used in any of the experiments are expected to have been produced by an individual heterozygous for these mutations (Table 1). In populations of organisms with a long history of outcrossing and large population sizes, a substantial proportion of the genetic load and inbreeding depression can be caused by recurrent mutation to recessive or nearly recessive lethals. In several species of Drosophila, for example, the ratio of the genetic load due to mildly detrimental genes to the genetic load due to lethals is usually less than one (Greenberg \& Crow, 1960; Simmons \& Crow, 1977). Lande \& Schemske (1985) showed that even a small amount of self-fertilization (on the order of a few per cent) can greatly reduce the equilibrium frequency of completely reces- sive lethals below that with complete random mating. An increase in the rate of self-fertilization has a much smaller effect on the reduction of the frequencies of partially dominant lethals. The freqencies of such alleles will be quite low even in outcrossing populations because most of these lethals are eliminated from the population as heterozygotes (Lande \& Schemske, 1985). For these theoretical reasons, lethals are expected to contribute relatively little to the total inbreeding depression in partially selfing populations. The results presented here on two partially selfing populations of $M$. guttatus are in accord with these predictions.

\section{Acknowledgements}

I am very grateful to my thesis advisors, Doug Schemske and Deborah Charlesworth, and to the members of my Committee, Steve Arnold, Brian Charlesworth, Russ Lande, and Mike Wade, for many helpful suggestions during the planning stages of this study and for comments on an early version of this manuscript. I would also like to thank Mark Johnston, Martin Morgan, Keith Karoly, Jerry Coyne, Sue Hattingh, David Houle, and Mike Lynch for many fruitful discussions and Sue Yamins, John Zdenek, and Sandra Suwanski for expert greenhouse care. This research was supported by grants from NSF (Dissertation Improvement Grant \# 88-05736), Sigma-Xi, and the Hinds Fund. Mike Lynch kindly arranged for the greenhouse space that I used at the University of Oregon in the summer of 1990.

\section{References}

ALLENDORF, F. W. 1976. Amount of polymorphism expected at duplicate loci. Genetics, 83, s1.

APIRION, D. AND ZOHARY, D. 1961. Chlorophyll lethals in natural populations of the orchard grass (Dactylis glomerata L.). A case of balanced polymorphism in plants. Genetics, 46, 393-399.

BRYAN, F. AND SOLTIS, D. E. 1987. Electrophoretic evidence for allopolyploidy in the fern Polypodium virginianum. Syst. Bot., 12, 553-561.

CHARLESWORTH, D. AND CHARLESWORTH, B. 1979. The evolutionary genetics of sexual systems in flowering plants. Proc. Roy. Soc. Lond. B, 205, 513-530.

CHARLESWORTH, D. AND CHARLESWORTH, B. 1987. Inbreeding depression and its evolutionary consequences. Ann. Rev. Ecol. Syst., 18, 237-268.

CHARLESWORTH, D., MORGAN, M. T. AND CHARLESWORTH, B. 1990. Inbreeding depression, genetic load and the evolution of outcrossing rates in a multi-locus system with no linkage. Evolution, 44, 1469-1489.

CHRISTIANSEN, F. B. AND FRYDENBERG, o. 1977. Selection-mutation balance for two nonallelic recessives producing an 
inferior double homozygote. Am. J. Hum. Genet., 29. 195-207.

ClAUSEN, R. E. AND CAMERON, D. R. 1950. Inheritance in Nicotiana tabacum: XXIII. Duplicate factors for chlorophyll production. Genetics, 35, 4-10.

CROW, J. F. 1964. More on the heterozygous effects of lethals in Drosophila populations. Am. Nat., 98, 447-449.

CROW, J. F. AND TEMIN, R. G. 1964. Evidence for the partial dominance of recessive lethal genes in natural populations of Drosophila Am. Nat., 98, 21-33.

CROW, J. F. AND simmons, M. J. 1983. The mutation load in Drosophila. In: Ashburner, M., Carson, H. L. and Thompson, J. N. (eds), The Genetics and Biology of Drosophila. Academic Press, London. pp. 1-35.

CRUMPACKER, D. w. 1967. Genetic load in maize (Zea mays L.) and other cross-fertilized plants and animals. Evol. Biol., 1, 306-423.

CURRAN, P. L. 1963. Balanced polymorphisms in Dactylis glomerata sub-species woronowii. Nature, 197, 105-106.

DEMEREC, M. 1923. Inheritance of white seedlings in maize. Genetics, 8, 561-593.

DOBZHANSKY, T. AND SPASSKY, B. 1968. Genetics of natural populations. XL. Heterotic and deleterious effects of lethals in populations of Drosophila pseudoobscura. Genetics, 59, 411-425.

DOBZHANSKY, T. AND WRIGHT, s. 1941. Genetics of natural populations. V. Relations between mutation rate and accumulation of lethals in populations of Drosophila pseudoobscura. Genetics, 26, 23-51.

FALCONER, D. S. 1981. Introduction to Quantitative Genetics. 2nd edn. Longman, London.

FERRIS, S. D. AND WHITT, G. S. 1977. Loss of duplicate gene expression after polyploidization. Nature, 265, 258-260.

FISHER, R. A. 1935. The sheltering of lethals. Am. Nat., 69, 446-455.

GANDERS, F. R. 1972. Heterozygosity for recessive lethals in homosporous fern populations: Thelypteris palustris and Onoclea sensibilis. Bot. J. Linn. Soc, 65, 211-221.

GASTONY, G. J. 1991. Gene silencing in a polyploid homosporous fern: paleopolyploidy revisited. Proc. Natl. Acad. Sci. U.S.A., 88, 1602-1605.

GREENBERG, R. AND CROW, J. F. 1960. A comparison of the effect of lethal and detrimental chromosomes from Drosophila populations. Genetics, 45, 1153-1168.

GUSTAFSSON, A. 1947. The advantageous effect of deleterious mutations. Hereditas, 33, 573-575.

HALDANE, J. B. S. 1933. The part played by recurrent mutation in evolution. Am. Nat., 42, 5-19.

HAYES, H. K. AND BREWBAKER, H. E. 1924. Frequency of mutations for chlorophyll-deficient seedlings in maize. J. Hered., 15, 497-502.

HEDRICK, P. W. 1987. Genetic load and the mating system in homosporous ferns, Evolution, 41, 1282-1289.

HOULE, D. 1989. Allozyme-associated heterosis in Drosophila melanogaster. Genetics, 123, 789-801.

JINKS, J. L. 1983. Biometrical genetics of heterosis. In: Frankel, R. (ed.), Heterosis: Reappraisal of Theory and Practice. Springer-Verlag, Berlin, pp. 1-46.

JØRGENSEN, J. H. AND JENSEN, H. P. 1986. The spontaneous chorophyll mutation frequency in Barley. Hereditas, $\mathbf{1 0 5}$, 71-72.

KIANG, Y. T. 1970. A natural population of Mimulus guttatus maintaining a high frequency of an albino lethal gene. $\mathrm{PhD}$ Dissertation, University of California, Berkeley.

KIANG, Y. T. 1972. Pollination study in a natural population of Mimulus guttatus. Evolution, 26, 308-310.

KIANG, Y. T. AND LIBBY, W. J. 1972. Maintenance of a lethal in a natural population of Mimulus guttatus. Am. Nat., 106, 351-367.

KLEKowSKI, E. J. 1970. Populational and genetic studies of a homosporous fern, Osmunda regalis. Am. J. Bot., 57, 1122-1138.

KLEKOWSKI, E. J. 1976. Genetics of recessive lethality in the fern, Osmunda regalis. J. Hered., 67, 146-148.

KLEKOWSKI, E. J. 1984. Mutational load in clonal plants: a study of two fern species. Evolution, 38, 417-426.

KLEKowsKI, E. J. 1988. Mutation, Developmental Selection, and Plant Evolution. Columbia University Press, New York.

LANDE, R. AND SCHEMSKE, D. W. 1985. The evolution of selffertilization and inbreeding depression in plants. I. Genetic models. Evolution, 39, 24-40.

LI, w.-H. 1980. Rate of gene silencing at duplicate loci: A theoretical study and interpretation of data from tetraploid fishes. Genetics, 95, 237-258.

LLOYD, D. G. 1979. Some reproductive factors affecting the selection of self-fertilization in plants. Am. Nat., 113, 67-79.

LYNCH, M. AND GABRIEL, w. 1990. Mutation load and survival of small population. Evolution, 44, 1725-1737.

MARUYAMA, T. AND TAKAHATA, N. 1981. Numerical studies of the frequency trajectories in the process of fixation of null genes at duplicated loci. Heredity, 46, 49-57.

MATHER, K. AND JINKS, J. L. 1982. Biometrical Genetics, Chapman and Hall, London.

MUKAI, T. AND BURDICK, A. B. 1959. Single gene heterosis associated with a second chromosome recessive lethal in Drosophila melanogaster. Genetics, 44, 211-232.

NEI, M. 1968. The frequency distribution of lethal chromosomes in finite populations. Proc. Natl. Acad. Sci., U.S.A., 60, 517-524.

NEI, M. 1969. Gene duplication and nucleotide substitution in evolution. Nature, 221, 40-41.

NEI, M. AND RoYchoudhury, A. K. 1973. Probability of fixation of nonfunctional genes at duplicate loci. Am. Nat., 107, $362-373$

oHNisHI, o. 1982. Population genetics of cultivated buckwheat, Fagopyrum esculentum Moench. I. Frequency of chlorophyll-deficient mutants in Japanese populations. Japanese. J. Genet., 57, 623-639.

oHNO, s. 1972. So much 'junk' DNA in our genome, In: Smith, H. H. (ed.), Brookhaven Symposia in Biology No. 23. Gordon and Breach, New York, pp. 366-370.

OHTA, T. AND COCKERHAM, C. c. 1974. Detrimental genes with partial selfing and effects on a neutral locus. Genet. Res., Camb. 23, 191-200.

PROUT, T. 1952. Selection against heterozygotes for autosomal lethals in natural populations of Drosophila willistoni. Proc. Natl. Acad. Sci., U.S.A., 38, 478-481. 
RIMAN, L. 1963. A synoptic survey of maize genes. Maydica, 8, 99-123.

ROBERTSON, A. AND NARAIN, P. 1971. The survival of recessive lethals in finite populations. Theor. Pop. Biol., 2, 24-50.

SCHNICK, S. M., MUKAI, T. AND BURDICK, A. B. 1960. Heterozygote viability of a second chromosome recessive lethal in Drosophila melanogaster. Genetics, 45, 315-329.

SCHULER, J. F. 1954. Natural mutations in inbred lines of maize and their heterotic effect. I. Comparison of parent, mutant and their $F_{1}$ hybrid in a highly inbred background. Genetics, 39, 908-922.

SIMMONS, M. J. AND CROW, J. F. 1977. Mutations affecting fitness in Drosophila populations. Ann. Rev. Genet., 11, 49-78.

soulé, M. 1986. Conservation Biology. Sinauer Association, Sunderland, MA.

SPRAGUE, G. F. 1983. Heterosis in maize: theory and practice. In: Frankel, R. (ed.), Heterosis: Reappraisal of Theory and Practice. Springer-Verlag, Berlin.

WERTH, C. R., GUTTMAN, S. I. AND EShBaUGH, W. H. 1985. Recurring origins of allopolyploid species in Asplenium. Science, 228, 731-733.

WERTH, C. R. AND WINDHAM, M. D. 1991. A model of divergent, allopatric speciation of polyploid Pteridophytes resulting from silencing of duplicate-gene expression. Am. Nat., 137, 515-526.
WETTSTEIN, D. V., HENNINGSEN, K. W., BOYNTON, J. E., KANNAGARA, G. C. AND NIELSEN, O. F. 1971. The genic control of chloroplast development in barley. In: Boardman, N. K. and Smillie, R. M.(eds), Autonomy and Biogenesis of Mitochondria and Chloroplasts. North Holland Press, The Hague, Netherlands, pp. 205-223.

WILliams, W. AND BROWN, A. G. 1956. Genetic response to selection in cultivated plants: gene frequencies in Prunus avium. Heredity, 10, 237-245.

WILLIS, J. H. 1991. The role of inbreeding depression in the evolution of two partially self-fertilizing populations of Mimulus guttatus. PhD Dissertation, University of Chicago.

WRIGHT, s. 1937. The distribution of genes in populations. Proc. Natl. Acad. Sci., U.S.A. 23, 307-320.

WRIGHT, s. 1969. Evolution and the Genetics of Populations, Vol. 2. The Theory of Gene Frequencies. University of Chicago Press, Chicago.

WRIGHT, s. 1977. Evolution and the Genetics of Populations, Vol. 3. Experimental Results and Evolutionary Deductions. University of Chicago Press, Chicago.

WRIGHT, S., DOBZHANSKY, T. AND HOVANITZ, w. 1942. Genetics of natural populations. VII. The allelism of lethals in the third chromosome of Drosophila pseudoobscura. Genetics, 27, 363-394. 